\title{
Osteonecrosis in Children and Adolescents With Acute Lymphoblastic Leukemia: Early Diagnosis and New Treatment Strategies
}

\author{
GIADA BIDDECI ${ }^{1}$, GERARDO BOSCO ${ }^{2}$, ELENA VAROTTO ${ }^{1}$, MARCO CORRADIN $^{3}$, \\ GIULIA GERANIO $^{1}$, GLORIA TRIDELLO ${ }^{4}$, MARTA PILLON ${ }^{1}$, ELISA CARRARO ${ }^{1}$, \\ GIACOMO GARETTO ${ }^{5}$, ROYA ASSADI $^{5}$, COSIMO GIGANTE $^{3}$ and MARIA CATERINA PUTTI ${ }^{1}$ \\ ${ }^{1}$ Department of Women's and Children's Health, Pediatric Haemato-Oncology, University of Padua, Padua, Italy; \\ ${ }^{2}$ Department of Biomedical Sciences, University of Padua, Padua, Italy; \\ ${ }^{3}$ Pediatric Orthopedic Unit, Orthopedic Surgery Department, University of Padua, Padua, Italy; \\ ${ }^{4}$ Pediatric Hematology Oncology, University Hospital, Verona, Italy; \\ ${ }^{5}$ ATIP Hyperbaric Medical Center, Biomedical Science Department, Padua, Italy
}

\begin{abstract}
Background/Aim: In the last few decades, treatment strategies for acute lymphoblastic leukemia (ALL) have been associated not only with improvement of prognosis, but also with an increasing rate of late complication as osteonecrosis $(\mathrm{ON})$. Herein, the cumulative incidence, risk factors, new conservative therapeutic strategies as hyperbaric oxygen therapy (HBO), and outcome of symptomatic ON were studied in pediatric patients with ALL. Patients and Methods: Between 2000 and 2017, 495 children and young adolescents with a diagnosis of ALL were evaluated. All the symptomatic patients underwent magnetic resonance imaging (MRI) to detect bone vascularization and structure. Results: Twenty-three out of 495 patients presented ON (4.6\%). ON was associated with an older age $(p<0.0001)$ and a higher steroid dose $(p=0.0013)$. All the patients underwent standard therapies and $\mathrm{HBO}$ was performed in 8 of 23 patients. During the follow-up, 15 patients were stable: 6 were totally asymptomatic, 5 complained of pain during activity, and 4 presented mild function limitation. Conclusion: Our data highlight the importance of early diagnosis of ON by screening MRI in asymptomatic patients, in order to start conservative treatment strategies. Moreover, HBO could have beneficial effects on ON patients.
\end{abstract}

Correspondence to: Gerardo Bosco, MD, Ph.D., Environmental Physiology and Medicine Laboratory, Department of Biomedical Sciences, University of Padova, Via Marzolo, 3, 35131 Padua, Italy. Tel: +39 0498275297, Fax: +39 0498275301, e-mail: gerardo. bosco@unipd.it

Key Words: Pediatric oncology, hematology, orthopedic surgery, hyperbaric oxygen therapy, MRI.
Osteonecrosis $(\mathrm{ON})$ is one of the most disabling late complications of pediatric acute lymphoblastic leukemia (ALL) treatment, with an incidence up to $17.6 \%$ in pediatric (1). Depending on the stage of ON, symptoms can range from asymptomatic to highly debilitating, with severe pain, limited range of joint motion up to joint destruction (2).

$\mathrm{ON}$ in children with ALL has a multifactorial origin; the necrosis of bone tissues due to vascular causes is considered important. The presumed pathogenic mechanism lies in altered bone vascularization, which leads to a demineralization and trabecular thinning of bone structure, causing mechanical failure (1). Glucocorticoid therapy has been identified as the main contributing factor to $\mathrm{ON}$. Steroid dose and administration rate (continuous versus intermittent) seem to be important, whereas the role of different steroid potency, e.g. dexamethasone (DXM) compared to prednisone $(\mathrm{PDN})$, is not clear $(3,4)$. According to many authors, DXM is not associated with increased incidence of ON (5). Moreover, L-asparaginase treatment may contribute to the impairment of blood circulation in the bone, as a consequence of a hypercoagulable state $(2,6,7)$.

$\mathrm{ON}$ is more frequent in older children, especially over 10 years of age and is associated with Caucasian ethnicity and impairment of ACP1, PAI-1 genes $(8,9)$. The impact of gender is still not clear; according to some studies, female gender is associated with increased risk of ON (1). With an incidence of $1.4 \%$ up to $17.6 \%(1,4)$, ON is more frequent after hematopoietic stem cell transplantation (HSCT), probably due to the high dose of steroids administered for this therapy (4). Moreover, ON rate is higher in screening studies (22\%), where magnetic resonance imaging (MRI) is performed in asymptomatic patients at fixed time points (10). ON is usually localized in the lower limbs joints, primarily knee and hip. This suggests that avascular necrosis mostly affects weight-bearing 
epiphyseal bone with a vulnerable blood supply (11). Multiple joint involvement is also common (4).

MRI is the gold-standard diagnostic tool to identify early stage $\mathrm{ON}$, when direct radiography is still negative $(12,13)$. Different radiological classifications have been proposed, but Association Research Circulation Osseus (ARCO) grading score is the most used $(14,15)$.

A standardized protocol treatment for ON does not exist (2). Anti-inflammatory drugs, vitamin D, and bisphosphonate play a role as supportive therapies. Nevertheless, $20-22 \%$ of patients with $\mathrm{ON}$ need a surgical approach after an average time of 2.2 years from diagnosis $(16,17)$. Surgery may decrease pain and improve mobility. In adults with $\mathrm{ON}$, joint decompression may be effective in preventing subsequent joint collapse (18). Recently, implantation of autologous osteogenic cells or osteochondral grafting has been described $(14,19)$. Moreover, hyperbaric oxygen therapy (HBO) has a beneficial impact on $\mathrm{ON}$ providing a higher oxygen concentration to all tissues and ischemic bone cells as well $(20,21)$. There is no evidence that $\mathrm{HBO}$ acts on tumor growth and recurrence, in vitro, while in vivo and clinical studies suggest a neutral effect of HBO on tumor growth (22). Instead, putative mechanisms and benefits have been found by modulating antioxidant and inflammatory responses (23-25).

$\mathrm{ON}$ treatment is still controversial and undefined. Given the uncertainties in this field, clinical and real-life reports are warranted. Randomized studies are difficult, due to the small number of affected patients and their heterogeneity. Herein, we studied the cumulative incidence, risk factors, new conservative therapeutic strategies, and outcome of symptomatic ON in pediatric patients with ALL. The prevalence and risk factors of $\mathrm{ON}$ in homogeneously treated children with ALL, were retrospectively analyzed to identify strategies for early diagnosis and precocious conservative treatment with $\mathrm{HBO}$.

\section{Patients and Methods}

Patients. We retrospectively evaluated 495 children and young adolescent ALL patients, diagnosed and treated at the Clinic of Pediatric Hematology-Oncology of Padua University Hospital between September 2000 and February 2017. Patients were treated according to the Protocols used in Associazione Italiana di EmatoOncologia Pediatrica (AIEOP) Centers: AIEOP ALL 2000 Protocol from 2000 to 2011 and AIEOP-BFM ALL 2009 Protocol from 2012 to February 2017. Informed consent was obtained from parents and adolescent patients, as approved by the local Ethical Committee. Age at diagnosis, gender, immunophenotype, treatment risk arm, HSCT in first remission, death or relapse, number and site of ON, and bone lesions at diagnosis were recorded for each patient.

Both chemotherapy protocols had similar backbones. Two different steroids were administered: PDN in the initial Induction phase and DXM later in the Delayed Intensification phase (Table I). Patients with a more aggressive leukemia, defined as "high risk" (HR), were treated with more intensive chemotherapy and higher doses of steroids. Each ALL patient presenting with symptoms (joint pain, functional limitation) underwent X-Ray and MRI examination. A pediatrician and an orthopedic surgeon independently classified $\mathrm{ON}$ radiological signs according to ARCO criteria. Controversial cases were monitored and re-evaluated within one to three months according to a flow-chart protocol developed in our Center (Figure 1). Radiological evaluation was repeated every 3-6 months, depending on severity and treatment. Clinical presentation of $\mathrm{ON}$ was graded using CTCAE criteria (26). At first, patients were treated with conservative methods, usually weight discharge. HBO therapy was administered using DRASS Galeazzi Model device (Livorno, Italy), as follows: daily administration of 3 fractions of $25 \mathrm{~min}$ at $\mathrm{O} 2100 \%$ alternated with $5 \mathrm{~min}$ of air at 2.5 absolute atmospheres (A.T.A), for at least 30 consecutive sessions. Surgical core decompression was performed for persisting pain or radiological images worsening. Joint replacement was chosen in case of progressive disease (27).

Statistical analysis. Demographic and clinical characteristics of patients were represented through descriptive methods: absolute frequencies and percentages were used for dichotomous and categorical variables, whereas continuous variables were expressed by median, range, mean, and standard deviation. We studied the association between the analyzed variables (age $\leq 10$ years or $>10$ years, gender, therapeutic risk group) and the onset of $\mathrm{ON}$ using the Chi-square test or Fisher test for categorical variables. Variables that were significant by univariate analysis were further studied by multivariate logistic regression analysis. Wilcoxon test was used to compare the dose of steroid received by patients with $\mathrm{ON}$. Variables with a $p$-value $<0.05$ were considered significant. The statistical analysis was performed using SAS v 9.4 software (SAS Institute Inc., Cary, NC, USA).

\section{Results}

The main demographic, hematological and clinical features of our patients (age, immunophenotype, risk group, bone injuries at leukemia onset, HSCT, relapse or death) are reported in Table II. Most of the ALL patients (76.2\%) were under 10 years of age $[p=0.001$; Odds ratio $(\mathrm{OR})=13.25, \mathrm{CI}=5.84$ 30.07). Seventy-six children (15.3\%) received HR therapy. Median follow-up was 38.3 months (range $=8-170$ ) at the time of this study. We identified ON in 23/495 patients (4.6\%); of them, 20 were over 10 years of age. The prevalence of ON was significantly higher in older children $(16.9 \% \mathrm{vs} .0 .8 \%$, $p<0.0001$ ), while it did not differ between the two genders. We found that $43 \%$ of ON patients had reached puberty (stage 3 ) and $13 \%$ had body mass index (BMI) $>15$; statistical significance could not be analyzed, since information about BMI were available only for ON patients.

HR patients showed an increased prevalence of ON (9/76, $11.8 \%)$ compared to NHR patients $(11 / 419,2.6 \%, p=0.0013)$ (Table II). The mean dose of DXM received was significantly higher in HR patients $(p=0.0015)$ compared to NHR group. Moreover, the mean PDN doses received by HR and NHR patients with ON were comparable. Transplanted patients represent a peculiar group; they received a significantly higher dose of PDN compared to the NHR and HR groups $(p=0.012)$, 
Table I. Steroids used in the treatment of ALL children: doses and length of administration.

\begin{tabular}{lcc}
\hline & PDN & DXM \\
\hline $\begin{array}{l}\text { Pre-phase } \\
\text { Dose }\end{array}$ & $60 \mathrm{mg} / \mathrm{m}^{2}$ & - \\
Duration & $7 \mathrm{days}$ & - \\
Induction & $60 \mathrm{mg} / \mathrm{m}^{2}$ & $10 \mathrm{mg} / \mathrm{m}^{2}$ \\
Dose & 28 days & 28 days \\
Duration & & (in T ALL NHR \\
& & in Protocol 2009) \\
Consolidation (HR patients) & - & $20 \mathrm{mg} / \mathrm{m}^{2}$ \\
Dose & - & 5 days, 3 times \\
Duration & & $10 \mathrm{mg} / \mathrm{m}^{2}$ \\
Delayed Intensification & - & NHR: 4 weeks \\
Dose & & HR: 3 weeks, 3 times \\
Duration & &
\end{tabular}

ALL, Acute lymphoblastic leukemia; PDN, prednisone; DXM, dexamethasone; HR, high risk; NHR, non-high risk.

and a similar dose of DXM compared to the HR group. Three patients presented $\mathrm{ON}$ after bone marrow transplantation: the prevalence of $\mathrm{ON}$ in this population is not significantly higher compared to other patients $(p=0.47)$, probably due to the exiguity of the sample. Two of 3 transplanted patients received very high doses of PDN $\left(5700 \mathrm{mg} / \mathrm{m}^{2}\right.$ and $4090 \mathrm{mg} / \mathrm{m}^{2}$, respectively) after HSCT because of graft versus host disease (GVHD); the third patient did not receive any additional dose of steroids; he had total body irradiation (TBI) as part the of conditioning therapy (Table II).

The majority of patients presented $\mathrm{ON}$ in the last part of the chemotherapy period (Delayed Intensification or Maintenance) or after stopping chemotherapy: median time of onset was 17 months (range=8-63) from diagnosis of ALL. At the time of diagnosis (Table III), all patients were symptomatic, usually severely: 5 patients presented only pain (CTCAE 2) and 18 patients presented pain and functional limitation (CTCAE 3). Most patients were classified in advanced radiological stages (ARCO 3-4:12 patients) at first examination. Six out of 23 children (26\%) showed a single site of $\mathrm{ON}$, whereas $17(74 \%)$ presented multiple sites at onset. Lower limbs were most frequently involved, in particular hips, knees and ankles.

Five patients with ON presented further additional sites at a subsequent time-point; clinical evolution during follow-up is also shown in Table III.

All patients were at first treated using conservative therapy. Joint discharge was prescribed to all children but was accomplished only in 13/23 (56.5\%) of them; $10 / 23$ (43.4\%) received anti-inflammatory drugs; occasional children received other therapies (vitamin D and calcium

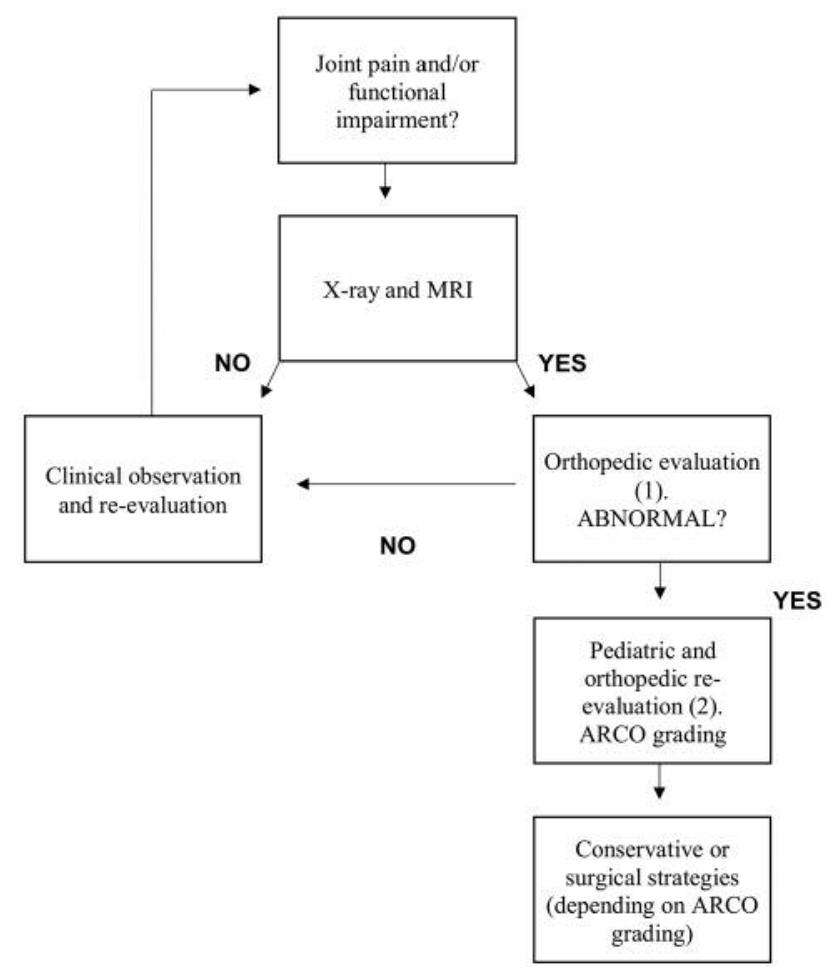

Figure 1. Diagnostic flow chart for osteonecrosis. MRI, Magnetic resonance imaging; ARCO, Association Research Circulation Osseus.

supplementation, physiotherapy, magneto-therapy) (Table IV). Only transient symptomatic improvement was obtained in some patients. In $8 / 23$ children (34.8\%) we administered HBO therapy, according to the availability of the procedure. Four out of the 8 children presented severe lesions ( 3 patients with ARCO 3, 1 patient with ARCO 4), 4 patients had mild-grade ON (3 patients with ARCO 2 and 1 patient with ARCO 1). Outcome of HBO therapy differed according to initial grading: 3 patients with mild grade of ON were stable at MRI controls; the 4 patients with severe lesions worsened and underwent joint replacement, one patient died early of a second neoplasia (mutation of p53 protein).

The median follow-up for all patients was 28.5 months (8170 months). Sixteen patients were stable throughout the years: 6 are now asymptomatic, 5 present only pain during physical activity and 4 have mild functional limitations.

Six out of 23 patients $(26 \%)$ presented at follow-up radiological and clinical worsening; another patient also complained of pain and functional limitation, in the presence of stable radiological findings. They all were considered CTCAE grade 4; 6 underwent joint replacement and one had articular drilling of femoral head. These 7 patients did not significantly differ from other ON patients in terms of age, puberty, gender and BMI. 
Table II. Main clinical features of acute lymphoblastic leukemia (ALL) patients; comparison with children affected by osteonecrosis (ON).

\begin{tabular}{|c|c|c|c|}
\hline & ALL patients & ON patients & Statistical significance [Method] \\
\hline Total patients (n) & 495 & 23 & \\
\hline \multicolumn{4}{|l|}{ Age (years) } \\
\hline Median age & 5.2 & 13.9 & \\
\hline Range & $(1.1-19.8)$ & $(5.2-19.1)$ & \\
\hline Age $<10$ years, $\mathrm{n}(\%)$ & $377 / 495(76.2 \%)$ & $3 / 377(0.8 \%)$ & $p=0.001$ \\
\hline Age $>10$ years, $n(\%)$ & $118 / 495(23.8 \%)$ & $20 / 118(16.9 \%)$ & [Multivariate analysis] \\
\hline \multicolumn{4}{|l|}{ Gender } \\
\hline Female & $224 / 495(45.2 \%)$ & $11 / 224(4.9 \%)$ & \multirow[t]{2}{*}{$p=0.8[$ Chi-square $]$} \\
\hline Male & $271 / 495(54.8 \%)$ & $12 / 271(4.4 \%)$ & \\
\hline \multicolumn{4}{|l|}{ Immunophenotype } \\
\hline $\mathrm{B}$ & $431 / 495(87 \%)$ & $20 / 431(4.6 \%)$ & \multirow[t]{2}{*}{$p=0.76[$ Chi-square $]$} \\
\hline $\mathrm{T}$ & $64 / 495(13 \%)$ & $3 / 64(4.7 \%)$ & \\
\hline Bone injuries at diagnosis & $11 / 495(2.2 \%)$ & 0 & \\
\hline \multicolumn{4}{|l|}{ Risk group } \\
\hline $\mathrm{HR}$ & $76 / 495(15.3 \%)$ & $9 / 76(11.8 \%)$ & \multirow[t]{2}{*}{$p=0.0013[$ Chi-square $]$} \\
\hline NHR & $419 / 495(84.7 \%)$ & $11 / 419(2.6 \%)$ & \\
\hline HSCT in 1 st remission & $46 / 495(9.3 \%)$ & $3 / 46(6.5 \%)$ & \multirow[t]{2}{*}{$p=0.47$ [Chi-square] } \\
\hline Death/ALL relapse & $49 / 495(9.9 \%)$ & $1 / 23(4.3 \%)$ & \\
\hline \multicolumn{4}{|l|}{ Steroid doses (mean dose) } \\
\hline \multicolumn{4}{|l|}{$\mathrm{PDN} \mathrm{mg} / \mathrm{m}^{2}$} \\
\hline $\mathrm{HR}$ & & 1698 & \multirow{3}{*}{$\begin{array}{c}\text { Mean dose of PDN } \\
\text { in HSCT > in NHR } \\
p=0.01 \text { [Wilcoxon test] }\end{array}$} \\
\hline NHR & & 1840 & \\
\hline HSCT & & 3863 & \\
\hline \multicolumn{4}{|l|}{$\mathrm{DXM} \mathrm{mg} / \mathrm{m}^{2}$} \\
\hline HR & & 527 & \multirow{5}{*}{$\begin{array}{c}\text { Mean dose of DXM } \\
\text { in HR }>\text { in NHR } \\
p=0.0015 \\
\text { in HSCT }>\text { in NHR } \\
p=0.0015 \text { [Wilcoxon test] }\end{array}$} \\
\hline NHR & & 234 & \\
\hline HSCT & & 550 & \\
\hline & & & \\
\hline & & & \\
\hline
\end{tabular}

HR, High-risk; NHR, non-high risk; HSCT, hematopoietic stem cell transplantation; PDN, prednisone; DXM, dexamethasone.

\section{Discussion}

The global prevalence of osteonecrosis in our monocentric series was similar to what is reported by other Groups, both after chemotherapy (1.4-7.6\%) and after HSCT (6.8\%) $(3,4$, 28, 29).

Since all our patients were diagnosed at onset of symptoms, in our report the incidence of $\mathrm{ON}$ at earlier stages is probably underestimated. Indeed, some studies have reported higher incidence (22\% after chemotherapy and $44 \%$ after HSCT), when radiological examinations were used as screening early in the course of treatment, especially among those patients older than 10 years $(10,28)$.

Literature describes female gender, age over 10 years, and high doses of steroids as risk factors for the development of $\mathrm{ON}$. It was speculated that the increase in estrogens in females could have a procoagulant effect, predisposing them to avascular necrosis (1). We could not confirm this finding, being females affected in the same rate of males in our series. In the present study, most patients with ON were older than 10 years and only occasionally ON was diagnosed at a younger age (5.7 and 9 years). This difference was statistically significant also in multivariate analysis, underlying the importance of age as a risk factor for $\mathrm{ON}$ $(\mathrm{OR}=13.25, \mathrm{CI}=5.84-30.07)$. We then can confirm the importance of older age as risk factor, irrespectively of gender $(1,4)$. This can be explained by the peculiar modalities of bone growth at adolescence, when the epiphyseal and metaphyseal vascular zones are separated by growth plates, with a reduced blood supply. Hormonal factors also contribute to modifying vascular resistance and consequently vascularization (1).

$\mathrm{ON}$ in our cohort was severe both clinically and radiologically. Moreover, it involved multiple sites at onset and spread to other sites at follow-up. Not only classical weight bearing bones were affected, but also foot, ankle and upper limbs, causing severe impairment and difficult treatment approach (Table IV). None of the children described by Salem had foot and arm involvement, while $10 \%$ of upper limbs involvement is described in the literature (11).

In the group of older children and adolescents, who experience fair percentages of event-free-survival (about 
Table III. Clinical features of osteonecrosis (ON) at onset and at follow-up.

\begin{tabular}{lcc}
\hline & at Onset & $\begin{array}{c}\text { at Follow-up } \\
(8-170 \text { months })\end{array}$ \\
\hline Site & & \\
Single & & \\
Multiple & $6 / 23(26 \%)$ & $5 / 23(21.7 \%)$ \\
Lower limbs & $17 / 23(74 \%)$ & $18 / 23(78.3 \%)$ \\
Hip & & \\
Knee & $10 / 23(43.5 \%)$ & $11 / 23(47.8 \%)$ \\
Pelvis & $13 / 23(56.5 \%)$ & $15 / 23(65.2 \%)$ \\
Ankle & $2 / 23(8.7 \%)$ & $2 / 23(8.7 \%)$ \\
Foot & $5 / 23(21.7 \%)$ & $6 / 23(26 \%)$ \\
Upper limbs & $2 / 23(8.7 \%)$ & $3 / 23(13 \%)$ \\
Elbow & & \\
Shoulder & $2 / 23(8.7 \%)$ & $3 / 23(13 \%)$ \\
ARCO & 0 & $3 / 23(13 \%)$ \\
1 & & \\
2 & $3 / 23(13 \%)$ & $2(8.7 \%)$ \\
& $8 / 23(34.8 \%):$ & $8(34.8 \%)$ \\
3 & 3 grade $2 \mathrm{c}$ & 6 grade $2 \mathrm{c}$ \\
4 & $11 / 23(47.8 \%)$ & $10(43.5 \%)$ \\
Total n. of worsened lesions & $1 / 23(4.4 \%)$ & $3(13 \%)$ \\
CTCAE & & $6(26 \%)$ \\
1 & & $6(26 \%)$ \\
2 & 0 & $5(21.7 \%)$ \\
3 & $5(21.7 \%)$ & $4(17.4 \%)$ \\
4 & $18(78.3 \%)$ & $1(4.4 \%)$ \\
Lost to follow-up & 0 & \\
\hline & & \\
& &
\end{tabular}

ARCO, Association Research Circulation Osseus; CTCAE, Common Terminology Criteria for Adverse Events.

$80 \%)$, ON represents a significant collateral burden in terms of chronic pain, impaired daily activities and quality of life (30). The high prevalence found in older children supports the necessity for specific diagnostic and therapeutic intervention in this age group.

Another relevant feature in our series is the incidence of $\mathrm{ON}$ in children treated in HR arm of our protocols. In particular, $11.8 \%$ of patients at HR experienced ON versus $2.6 \%$ of NHR patients. This difference was statistically significant in univariate analysis, but not in multivariate analysis, probably due to the differences regarding age of patients and steroid doses between the two groups. HR patients were significantly older than NHR; considering ON only in HR patients $>10$ years, the prevalence is $30.4 \%(7 / 23)$. Moreover, HR patients received higher doses of DXM than NHR, but the same dose of PDN. The importance of steroid therapy has been reported to be one of the main causes of $\mathrm{ON}$, both in leukemia patients and in other diseases $(2,3)$. Glucocorticoid therapy induces a hypercoagulable state and interacts with other chemotherapy agents (L-asparaginase, methotrexate) $(2,6)$. The role of the different potency of steroid drugs in the development of $\mathrm{ON}$ is controversial. In fact some authors state that DXM is associated with a higher
Table IV. Conservative and surgical therapies in patients with osteonecrosis $(\mathrm{ON})$

\begin{tabular}{lc}
\hline Therapies & $\begin{array}{c}\text { Patients with ON } \\
(\mathrm{n}=23)\end{array}$ \\
\hline Conservative therapies & $23 / 23(100 \%)$ \\
- Joint discharge & $13(56.5 \%)$ \\
- Anti-inflammatory therapies & $10(43.5 \%)$ \\
- Vitamin D/calcium & $5(21.7 \%)$ \\
- Hyaluronic acid & $2(8.7 \%)$ \\
- Physiotherapy & $3(13 \%)$ \\
- Magneto therapy & $1(4.3 \%)$ \\
& \\
Hyperbaric therapy & $8(34.8 \%)$ \\
Surgery & \\
- Articular drilling & $1(4.3 \%)$ \\
- Joint prosthesis & $6(26 \%)$ \\
\hline
\end{tabular}

incidence of ON: the COG group only found a difference in incidence of $\mathrm{ON}$ when using DXM during induction phase for patients over 10 years $(31,32)$. On the other hand, the BFM group found no difference between patients receiving PDN and DXM $(3,4)$. In our experience all patients received both PDN and DXM in two different time points of treatment. All children received similar doses of PDN, while HR patients received a higher dose of DXM. Moreover, DXM was given to HR in multiple courses over a period of about 6 months. Both doses and modality of administration can be responsible for the ON effect (33).

Forty-six patients of our series underwent HSCT in first remission; 3 of them (6.5\%) experienced ON. All of them were HR patients and had received higher doses of DXM. Two had received additional steroid therapy (usually PDN) as a treatment of transplant-related complications $(28,34)$.

In the experience of COG group any attempt to reduce the dose of steroids was successful in avoiding the onset of ON, but at the price of lower rates of cure. It showed a reduction in the $\mathrm{ON}$ incidence with the administration of intermittent DXM treatment instead of continuous steroids (days 1-7 and 15-21) at the same doses, but with higher rate of relapse (32). It is thus difficult to reduce ON without hampering the hematological results of chemotherapy protocols. However, by identifying children at higher risk of $\mathrm{ON}$, it is possible to develop strategies for early screening. This might be useful only if successful treatment strategies are available.

There is no standard of care for the treatment of $\mathrm{ON}$ in children with ALL, especially for the early stages; meanwhile HBO showed itself to be safe and effective in most patients even those dose immunocompromised or critical ill $(35,36)$. Our preliminary experience in HBO (3 
patients included in the present study and treated until 2014) suggested its implementation in our current treatment approach. Joint discharge, which was prescribed to all children, was not applied by almost $1 / 3$ of them, who continued to lead almost normal activity. This suggests that, at least in some patients, pain and functional limitations were tolerable as demonstrated also at clinical follow-up. Others have found joint discharge is not useful in reducing the progression of ON (37). Analgesic therapy is also frequently used to reduce pain and functional limitation. The efficacy of bisphosphonates, used in adults for osteoporosis, arthrosis, algo-distrophic syndrome and post-traumatic avascular necrosis, is still debated on children: pain reduction and functional improvement is described, but without radiological improvement $(2,13,34)$. These drugs show a prolonged anti-osteoclastic effect; clodronate also has an anti-inflammatory effect with inhibition of cytokine release (38). However, their use does not show any effect on ON progression. In a previous study, we used biphosphonate only rarely and we seldom found it effective (39).

Patients with severe symptomatic $\mathrm{ON}$ or progressive disease $(30 \%)$ required surgical intervention. None of them have been subjected to revision until now. Most reported joint replacements are done within three years from $\mathrm{ON}$ diagnosis. A multicenter study showed that $37 \%$ of patients with joint replacement need a second surgery within 6 months from the first one (16). There is thus a general agreement to postpone hip replacement to a later age (40, 41). Articular drilling, core decompression together with stem cell therapy have been proposed (27). All these interventions require that $\mathrm{ON}$ is identified at early stages and their role is still not fully cleared.

In our experience, only children with early stage-ON could benefit from HBO treatment. Three out of 4 patients with mild ON (ARCO 1,2), treated by HBO therapy, did not evolve either clinically or at MRI. Half of our children were identified at late stages (ARCO 3-4) and most of them were highly symptomatic (CTCAE 3 ). Four of them received HBO therapy without success.

$\mathrm{HBO}$ is frequently used in adult patients for $\mathrm{ON}$ due to different causes. The mechanism of HBO action is still unclear, but seems to increase neo-vascularization in ischemic tissues, osteoblastic proliferation in ischemic bone modulating oxygen free radicals (42-44). Historically, it has been used to avoid dysbaric osteonecrosis and in osteomyelitis; it is well used in chronic bone pathology, as for osteoradionecrosis, bisphosphonate osteonecrosis of the jaw (45). HBO is prescribed in the treatment of non-healing lesions via reactive oxygen and nitrogen species modulation (44), but recently there is speculation that the underlying HBO mechanism is related to an augmented signaling for bone turnover and osteoclast differentiation (20, 43). In Europe, HBO is recognized with a level of evidence B and regularly used in adults affected by idiopathic ON diagnosed at early stages (ARCO 1, 2a/b), obtaining the alleviation of pain, functional disabilities and radiological images $(21,46)$.

The stability of clinical and radiological picture after HBO that was observed in early stages $\mathrm{ON}$ suggests the use of $\mathrm{HBO}$ in combination with screening strategies. In fact, screening studies have shown a higher prevalence of radiological abnormalities during ALL treatment, most of which can evolve into overt ON $(10,47)$. Therefore, the combined use of early screening in a selected ALL population (older children and HR cases) together with $\mathrm{HBO}$ treatment, might be useful in avoiding the worsening of bone lesions at an early stage.

In conclusion, our experience shows the importance of $\mathrm{ON}$ as a mid-term complication of ALL therapy, with a strong impact on quality of life. Its detection could be improved by screening strategies, especially in older children and HR patients, for whom HBO could be considered a conservative treatment. However, HBO efficacy should be confirmed with further larger studies.

\section{Conflicts of Interest}

Authors have no conflict of interest to declare.

\section{Authors' Contributions}

GB, GBo and MCP conceived and designed the experiments. GR, RA, EV and MC performed the experiments. GGe, GT, MP and EC analyzed the data. CG, GG, RA contributed materials. GB, GBo and MCP wrote the paper. All authors approved the final version of the manuscript.

\section{Acknowledgements}

The Authors wish to thank Dr. Alex Rizzato for the editorial efforts.

\section{References}

1 Kunstreich M, Kummer S, Laws H-J, Borkhardt A and Kuhlen M: Osteonecrosis in children with acute lymphoblastic leukemia. Haematologica 101: 1295-1305, 2016. PMID: 27742768, DOI: 10.3324/haematol.2016.147595.

2 te Winkel ML, Pieters R, Wind E-JD, Bessems JHJM and van den Heuvel-Eibrink MM: Management and treatment of osteonecrosis in children and adolescents with acute lymphoblastic leukemia. Haematologica 99: 430-436, 2014. PMID: 24598854, DOI: 10.3324/haematol.2013.095562.

3 Moricke A, Zimmermann M, Valsecchi MG, Stanulla M, Biondi A, Mann G, Locatelli F, Cazzaniga G, Niggli F, Arico M, Bartram CR, Attarbaschi A, Silvestri D, Beier R, Basso G, Ratei R, Kulozik AE, Lo Nigro L, Kremens B, Greiner J, Parasole R, Harbott J, Caruso R, von Stackelberg A, Barisone E, Rossig C, Conter V and Schrappe M: Dexamethasone vs prednisone in induction treatment of pediatric ALL: results of the randomized trial AIEOP-BFM ALL 2000. Blood 127: 2101-2112, 2016. PMID: 26888258, DOI: 10.1182/blood-2015-09-670729. 
4 Girard P, Auquier P, Barlogis V, Contet A, Poiree M, Demeocq F, Berbis J, Herrmann I, Villes V, Sirvent N, Kanold J, Chastagner P, Chambost H, Plantaz D and Michel G: Symptomatic osteonecrosis in childhood leukemia survivors: prevalence, risk factors and impact on quality of life in adulthood. Haematologica 98: 1089-1097, 2013. PMID: 23645686, DOI: 10.3324/haematol.2012.081265.

5 Strauss AJ, Su JT, Dalton VMK, Gelber RD, Sallan SE and Silverman LB: Bony Morbidity in Children Treated for Acute Lymphoblastic Leukemia. J Clin Oncol 19: 3066-3072, 2001. PMID: 11408503, DOI: 10.1200/JCO.2001.19.12.3066.

6 Vrooman LM, Stevenson KE, Supko JG, O’Brien J, Dahlberg SE, Asselin BL, Athale UH, Clavell LA, Kelly KM, Kutok JL, Laverdière C, Lipshultz SE, Michon B, Schorin M, Relling M V, Cohen HJ, Neuberg DS, Sallan SE and Silverman LB: Postinduction dexamethasone and individualized dosing of Escherichia Coli L-asparaginase each improve outcome of children and adolescents with newly diagnosed acute lymphoblastic leukemia: results from a randomized study--DanaFarber Cancer Institute ALL Consortium Protocol 00-01. J Clin Oncol 31: 1202-1210, 2013. PMID: 23358966, DOI: 10.1200/ JCO.2012.43.2070.

7 Sehgal S, Sharma S, Chandra J and Nangia A: Coagulation profile during induction chemotherapy in childhood acute lymphoblastic leukemia. Indian J Pathol Microbiol 60: 50-56, 2017. PMID: 28195091, DOI: 10.4103/0377-4929.200029.

8 French D, Hamilton LH, Mattano LA, Sather HN, Devidas M, Nachman JB, Relling M V and Children's Oncology Group: A PAI-1 (SERPINE1) polymorphism predicts osteonecrosis in children with acute lymphoblastic leukemia: a report from the Children's Oncology Group. Blood 111: 4496-4499, 2008. PMID: 18285546, DOI: 10.1182/blood-2007-11-123885.

9 Karol SE, Yang W, Van Driest SL, Chang TY, Kaste S, Bowton E, Basford M, Bastarache L, Roden DM, Denny JC, Larsen E, Winick N, Carroll WL, Cheng C, Pei D, Fernandez CA, Liu C, Smith C, Loh ML, Raetz EA, Hunger SP, Scheet P, Jeha S, Pui C-H, Evans WE, Devidas M, Mattano LA and Relling M V.: Genetics of glucocorticoid-associated osteonecrosis in children with acute lymphoblastic leukemia. Blood 126: 1770-1776, 2015. PMID: 26265699, DOI: 10.1182/blood-2015-05-643601.

10 Kaste SC, Pei D, Cheng C, Neel MD, Bowman WP, Ribeiro RC, Metzger ML, Bhojwani D, Inaba H, Campbell P, Rubnitz JE, Jeha S, Sandlund JT, Downing JR, Relling M V, Pui C-H and Howard SC: Utility of early screening magnetic resonance imaging for extensive hip osteonecrosis in pediatric patients treated with glucocorticoids. J Clin Oncol 33: 610-615, 2015. PMID: 25605853, DOI: 10.1200/JCO.2014.57.5480.

11 Salem KH, Brockert A-K, Mertens R and Drescher W: Avascular necrosis after chemotherapy for haematological malignancy in childhood. Bone Joint J 95-B: 1708-1713, 2013. PMID: 24293604, DOI: 10.1302/0301-620X.95B12.30688.

12 Markisz JA, Knowles RJ, Altchek DW, Schneider R, Whalen JP and Cahill PT: Segmental patterns of avascular necrosis of the femoral heads: early detection with MR imaging. Radiology 162: 717-720, 1987. PMID: 3809485, DOI: 10.1148/ radiology.162.3.3809485.

13 Mitchell MD, Kundel HL, Steinberg ME, Kressel HY, Alavi A and Axel L: Avascular necrosis of the hip: comparison of MR, CT, and scintigraphy. AJR Am J Roentgenol 147: 67-71, 1986. PMID: 3487233, DOI: 10.2214/ajr.147.1.67
14 Roth A, Beckmann J, Bohndorf K, Fischer A, Heiß C, Kenn W, Jäger M, Maus U, Nöth U, Peters KM, Rader C, Reppenhagen S, Smolenski U, Tingart M, Kopp I, Sirotin I and Breusch SJ: S3-Guideline non-traumatic adult femoral head necrosis. Arch Orthop Trauma Surg 136: 165-174, 2016. PMID: 26667621, DOI: $10.1007 / \mathrm{s} 00402-015-2375-7$.

15 Trăistaru MR, Kamal D, Kamal KC, Rogoveanu OC, Popescu $\mathrm{M}$, Bondari S, Alexandru DO, Ionovici $\mathrm{N}$ and Grecu DC: Imaging and histopathological aspects in aseptic osteonecrosis of the femoral head. Rom J Morphol Embryol 56: 1447-1453, 2015. PMID: 26743293.

16 Heneghan MB, Rheingold SR, Li Y, Seif AE, Huang Y-S, McLeod L, Wells L, Fisher BT and Aplenc R: Treatment of Osteonecrosis in Children and Adolescents With Acute Lymphoblastic Leukemia. Clin Lymphoma Myeloma Leuk 16: 223-229.e2, 2016. PMID: 27021949, DOI: 10.1016/ j.clml.2015.12.009.

17 Patel B, Richards SM, Rowe JM, Goldstone AH and Fielding AK: High incidence of avascular necrosis in adolescents with acute lymphoblastic leukaemia: a UKALL XII analysis. Leukemia 22: 308-312, 2008. PMID: 17989709, DOI: 10.1038/ sj.leu.2405032.

18 Landgraeber S, Warwas S, Claßen T and Jäger M: Modifications to advanced Core decompression for treatment of Avascular necrosis of the femoral head. BMC Musculoskelet Disord 18: 479, 2017. PMID: 29162080, DOI: 10.1186/s12891-017-1811-y.

19 Görtz S, De Young AJ and Bugbee WD: Fresh Osteochondral Allografting for Steroid-associated Osteonecrosis of the Femoral Condyles. Clin Orthop Relat Res 468: 1269-1278, 2010. PMID: 20143191, DOI: 10.1007/s11999-010-1250-7.

20 Camporesi E, Vezzani G, Zanon V, Manelli D, Enten G, Quartesan S and Bosco G: Review on hyperbaric oxygen treatment in femoral head necrosis. Undersea Hyperb Med 44: 497-508, 2017. PMID: 29281187.

21 Mathieu D, Marroni A and Kot J: Tenth European Consensus Conference on Hyperbaric Medicine: preliminary report. Diving Hyperb Med 46: 122-123, 2016. PMID: 27335005.

22 Feldmeier J, Carl U, Hartmann K and Sminia P: Hyperbaric oxygen: does it promote growth or recurrence of malignancy? Undersea Hyperb Med 30: 1-18, 2003. PMID: 12841604.

23 Camporesi EM and Bosco G: Hyperbaric oxygen pretreatment and preconditioning. Undersea Hyperb Med 41: 259-263, 2014. PMID: 24984322.

24 Bosco G, Guizzon L, Yang Z, Camporesi E, Casarotto A, Bosio C, Mangar D, Chen C, Cannato M, Toniolo L, Garetto G, Nasole $\mathrm{E}$ and Bassi C: Effect of hyperbaric oxygenation and gemcitabine on apoptosis of pancreatic ductal tumor cells in vitro. Anticancer Res 33: 4827-4832, 2013. PMID: 24222119.

25 Bosco G, Vezzani G, Mrakic Sposta S, Rizzato A, Enten G, Abou-Samra A, Malacrida S, Quartesan S, Vezzoli A and Camporesi E: Hyperbaric oxygen therapy ameliorates osteonecrosis in patients by modulating inflammation and oxidative stress. J Enzyme Inhib Med Chem 33: 1501-1505, 2018. PMID: 30274530, DOI: 10.1080/14756366.2018.1485149.

26 Zhong X, Lim EA, Hershman DL, Moinpour CM, Unger J, Lee SM, Zhong X, Lim EA, Hershman DL, Moinpour CM, Unger J and Lee SM: Identifying severe adverse event clusters using the National Cancer Institute's common terminology criteria for adverse events. J Oncol Pract 12: e270-80, 245-246, 2016. PMID: 26907453, DOI: 10.1200/JOP.2015.006106. 
27 Rackwitz L, Eden L, Reppenhagen S, Reichert JC, Jakob F, Walles H, Pullig O, Tuan RS, Rudert M and Nöth U: Stem celland growth factor-based regenerative therapies for avascular necrosis of the femoral head. Stem Cell Res Ther 3: 7, 2012. PMID: 22356811. DOI: 10.1186/scrt98.

28 Kaste SC, Shidler TJ, Tong X, Srivastava DK, Rochester R, Hudson MM, Shearer PD and Hale GA: Bone mineral density and osteonecrosis in survivors of childhood allogeneic bone marrow transplantation. Bone Marrow Transplant 33: 435-441, 2004. PMID: 14716354, DOI: 10.1038/sj.bmt.1704360.

29 Padhye B, Dalla-Pozza L, Little DG and Munns CF: Use of zoledronic acid for treatment of chemotherapy related osteonecrosis in children and adolescents: a retrospective analysis. Pediatr Blood Cancer 60: 1539-1545, 2013. PMID: 23625773, DOI: $10.1002 / p b c .24563$.

30 Pui C-H, Yang JJ, Hunger SP, Pieters R, Schrappe M, Biondi A, Vora A, Baruchel A, Silverman LB, Schmiegelow K, Escherich G, Horibe K, Benoit YCM, Izraeli S, Yeoh AEJ, Liang D-C, Downing JR, Evans WE, Relling MV and Mullighan CG: Childhood Acute Lymphoblastic Leukemia: Progress Through Collaboration. J Clin Oncol 33: 2938-2948, 2015. PMID: 26304874, DOI: 10.1200/JCO.2014.59.1636.

31 Bostrom BC, Sensel MR, Sather HN, Gaynon PS, La MK, Johnston K, Erdmann GR, Gold S, Heerema NA, Hutchinson RJ, Provisor AJ, Trigg ME and Children's Cancer Group: Dexamethasone versus prednisone and daily oral versus weekly intravenous mercaptopurine for patients with standard-risk acute lymphoblastic leukemia: a report from the Children's Cancer Group. Blood 101: 3809-3817, 2003. PMID: 12531809, DOI: 10.1182/blood-2002-08-2454

32 Mattano LA, Devidas M, Nachman JB, Sather HN, Hunger SP, Steinherz PG, Gaynon PS, Seibel NL and Children's Oncology Group: Effect of alternate-week versus continuous dexamethasone scheduling on the risk of osteonecrosis in paediatric patients with acute lymphoblastic leukaemia: results from the CCG-1961 randomised cohort trial. Lancet Oncol 13: 906-915, 2012. PMID: 22901620, DOI: 10.1016/S1470-2045(12)70274-7.

33 Ramsey LB, Janke LJ, Payton MA, Cai X, Paugh SW, Karol SE, Kamdem Kamdem L, Cheng C, Williams RT, Jeha S, Pui C-H, Evans WE and Relling M V: Antileukemic Efficacy of Continuous vs Discontinuous Dexamethasone in Murine Models of Acute Lymphoblastic Leukemia. PLoS One 10: e0135134, 2015. PMID: 26252865, DOI: 10.1371/journal.pone.0135134.

34 Faraci M, Calevo MG, Lanino E, Caruso S, Messina C, Favr C, Iori A, Santaron S, Bonanomi S, Rondelli R, Dini G, Haupt R and AIEOP-SCT Group: Osteonecrosis after allogeneic stem cell transplantation in childhood. A case-control study in Italy. Haematologica 91: 1096-1099, 2006. PMID: 16885050.

35 Cesca E, Garetto G, Frascella E, Cesaro S, Dall'igna P and Cecchetto G: Hyperbaric oxygen treatment of superficial soft tissue lesions in children with oncologic disease. Pediatr Rep 4: e1, 2012. PMID: 22690301, DOI: 10.4081/pr.2012.e1.

36 Bosco G, Garetto G, Rubini A, Paoli A, Dalvi P, Mangar D and Camporesi EM: Safety of transport and hyperbaric oxygen treatment in critically-ill patients from Padua hospitals into a centrally-located, stand-alone hyperbaric facility. Diving Hyperb Med 46: 155-159, 2016. PMID: 27723016.
37 Petrigliano FA and Lieberman JR: Osteonecrosis of the hip: novel approaches to evaluation and treatment. Clin Orthop Relat Res 465: 53-62, 2007. PMID: 27723016.

38 Manzano-Moreno FJ, Ramos-Torrecillas J, De Luna-Bertos E, Reyes-Botella C, García-Martínez O and Ruiz C: Effect of clodronate on antigenic profile, growth, and differentiation of osteoblast-like cells. J Oral Maxillofac Surg 74: 1765-1770, 2016. PMID: 27109708, DOI: 10.1016/j.joms.2016.03.028.

39 Greggio NA, Pillon M, Varotto E, Zanin A, Talenti E, Palozzo AC, Calore E and Messina C: Short-term bisphosphonate therapy could ameliorate osteonecrosis: a complication in childhood hematologic malignancies. Case Rep Med 2010: 206132, 2010. PMID: 20589085, DOI: 10.1155/2010/206132.

40 Mihalko WM, Wimmer MA, Pacione CA, Laurent MP, Murphy $\mathrm{RF}$ and Rider C: How have alternative bearings and modularity affected revision rates in total hip arthroplasty? Clin Orthop Relat Res 472: 3747-3758, 2014. PMID: 25070918, DOI: 10.1007/s11999-014-3816-2

41 Mont MA, Pivec R, Banerjee S, Issa K, Elmallah RK and Jones LC: High-Dose Corticosteroid Use and Risk of Hip Osteonecrosis: Meta-Analysis and Systematic Literature Review. J Arthroplasty 30: 1506-1512.e5, 2015. PMID: 25900167, DOI: 10.1016/j.arth.2015.03.036.

42 Bosco G, Yang Z, Nandi J, Wang J, Chen C and Camporesi EM: Effects of hyperbaric oxygen on glucose, lactate, glycerol and antioxidant enzymes in the skeletal muscle of rats during ischaemia and reperfusion. Clin Exp Pharmacol Physiol 34: 70-76, 2007. PMID: 17201738, DOI: 10.1111/j.1440-1681.2007.04548.x.

43 Vezzani G, Quartesan S, Cancellara P, Camporesi E, Mangar D, Bernasek T, Dalvi P, Yang Z, Paoli A, Rizzato A and Bosco G: Hyperbaric oxygen therapy modulates serum OPG/RANKL in femoral head necrosis patients. J Enzyme Inhib Med Chem 32: 707711, 2017. PMID: 28385082, DOI: 10.1080/14756366.2017. 1302440.

44 Camporesi EM and Bosco G: Mechanisms of action of hyperbaric oxygen therapy. Undersea Hyperb Med 41: 247-252. PMID: 24984320.

45 Freiberger JJ, Padilla-Burgos R, McGraw T, Suliman HB, Kraft KH, Stolp BW, Moon RE and Piantadosi CA: What is the role of hyperbaric oxygen in the management of bisphosphonaterelated osteonecrosis of the jaw: a randomized controlled trial of hyperbaric oxygen as an adjunct to surgery and antibiotics. J Oral Maxillofac Surg 70: 1573-1583, 2012. PMID: 22698292, DOI: $10.1016 /$ j.joms.2012.04.001.

46 Camporesi EM, Vezzani G, Bosco G, Mangar D and Bernasek TL: Hyperbaric Oxygen Therapy in Femoral Head Necrosis. J Arthroplasty 25: 118-123, 2010. PMID: 20637561, DOI: 10.1016/j.arth.2010.05.005.

47 Sansgiri RK, Neel MD, Soto-Fourier M and Kaste SC: Unique MRI findings as an early predictor of osteonecrosis in pediatric acute lymphoblastic leukemia. AJR Am J Roentgenol 198: W432-439, 2012. PMID: 22528924, DOI: 10.2214/AJR.11.7367.

Received January 8, 2019

Revised February 7, 2019

Accepted February 13, 2019 